logg's explanation, I think the very large majority of the medical profession must also have lived under the error that the Battle Creek Sanitarium Co., Ltd., was a corporation owning the Battle Creek Sanitarium or was a subsidiary corporation.

After writing my letter to The Jounnal, I had an agent answer an advertisement of the Battle Creek Sanitarium Co., Ltd. In reply I received a symptom blank to be filled out and a request to send $\$ 5.00$ for a supply of food, "which our expert dietitians will select." I filled out this blank showing a person in normal health without bad habits, and sent it and the $\$ 5.00$. The only answers which possibly could have been distorted into evidence of dyspepsia were, "Sometimes sleepy," in reply to "Have you pain or heaviness after eating?" and "Drowsiness at times" in reply to "Do you suffer after eating from headache, drowsiness, etc., etc.?" Do you suppose there is a person living who is not sometimes sleepy, or who is not drowsy at times after eating!

In reply to this symptom blank I received a supply of foodstuffs and rarious literature. One letter which jurported to be an individual letter addressed to the patient, began "The foods have been selected by our dietitians for your particular use." In addition there was a twenty-page letter, apparently a personal typewritten letter, in which there was a lot of instructions and advice addressed to the patient. 'This began, "From the statements made on your information blank, it appears that you are suffering from delayed digestion resulting in mal-assimilation, etc." There was also included "A blank report of progress for the dietetic department," to be filled out by the patient and returned, presumably for further information. In about ten days there came a follow-up letter containing, among other things, "Let us know at once any symptoms which are indicated on the report blank."

This, of course, is making an effort to treat people by mail; but it is more than that. By reverting to their advertisement it will be seen that they request replies both from the sick and those who wish to remain well, and in my particular case they were notifying a person, whose symptom blank showed normal health, that he was suffering from "mal-assimilation"and a lot of other big words-and were then going ahead to treat him. This comes precious near trying to persuade people that they are sick, in order to cure them, or at least in order to have them for patients, or, we will say, purchasers of their goods; and in so doing it comes very close to the practices of the worst types of medical charlatans. To undertake to prescribe for people by mail is bad enough from the standpoint of the medical profession, but to tell them that they are sick in order to sell them things is the limit.

Now, as to the confusion with the Battle Creek Sanitariumnot $m y$ confusion, because, although I knew no better, I referred to nobody but the signer of the advertisement-but as to the confusion which must inevitably take place in the minds of the people who read these advertisements and get this literature. The letters sent out with their foods, and advice, were written on stationery with letter heads like "Battle Creek Sanitarium Company, Ltd., Battle Creek, Michigan, Department of Dietetics," with pictures of the sanitarium as part of most of the letter-heads. There was enclosed a book entitled, "The Simple Life, .. . . The Battle Creek Idea." In this there was a two-page illustration of the Battle Creek Sanitarium. The third sentence on the first page of the letter-press 0 . this booklet is "The expenditure of vier a million and a half dollars in the creation of the Battle (reek Sanitarium was possible only because of the wonderful results secured." All through this bonklet are references to the "Battle Creek Idea," the "Battle Creek System," and more than once reference is made to the "Battle Creek Sanitarium," not to "The Battle Creek Sanitarium Co., Ltd." There is nothing in this booklet that I fourd to indicate that all this stuff is not put out by the Battle Creek Sanitarium. On the contrary, I could get no other idea from the booklet, from the other literature, and from the labels on most of the packages, than that the design was to make the credulous believe that these things were issued by the Battle Creek Sanitarium.

Another leafiet which I received is chiefly an advertisement of a book by Dr. Kellogg, "The Stomach." "Dr. Kellogg, superintendent of the great Battle Creek Sanitarium, wrote this book. . ." On one of the symptom blanks which they sent out, with an offer to furnish a supply of proper foods for $\$ 5$, is stuck an insert in red ink, saying, "Use this blank and secure "The Stomach' free." On the fourth page of this leaf. let advertising "The Stomach" there are several testimonials. In one of them occurs the following sentence: "I can not say but one thing of all that has been sent me from the Battle Creek Sanitarium." I can not resist quoting another sentence from this same testimonial: "The 'Good Health' came last night, and like all else it is beautiful, good and true." (How true this rings to the average medical testimonial with its bad grammar and bathos).

Now, unless the Battle Creek Sanitarium proposes to stand for such methods, it seems to me absolutely necessary that its name be eliminated from the company issuing these food products. If there is any criticism from the professional standpoint to be attached to what the Battle Creek Sanitarium Co., Ltd., is doing, it is inevitable that this criticism must reflect on the Battle Creek Sanitarium, so long as the food company does business under its present name; the only way the Battle Creek Sanitarium can escape the conviction that it is behind this food company is to take its name entirely out of this company.

The logic of the situation indeed, compels me to go further, and to believe that neither the Battle Creek Sanitarium nor the medical men in association with the sanitarium can maintain their ethical character in the eyes of the profession, unless the sanitarium is able in some way to stop the exploitation of its reputation in the way it has been exploited by the Battle Creek Sanitarium Co., Jtd., or, better, make the company selling its product radically change its methods.

I am as glad as anyloody that Dr. Kellogg and the Battle Creek Sanitarium are independent of the Battle Creek Sanitarium Co., Itd., and I deplore as much as any one the fact that they are unwittingly laid open to what Dr. Kellogg ealls "censure entirely just." And I hope that in the interest of their professional dignity they will be able to prevent the further use of the repultation of the Battle Creek Sanitarium in the ways which I lave described above. W. A. Puser.

\section{The Country Doctor.}

Gum Sprixg, VA., June 16, 1906.

To the Editor:-I am very glad to note in Tre JournaL, June 2, 1906, page 1711, Dr. M. W. Pearson's reply to Dr. John C. Wilson on "The Country Doctor." I am confident that Dr. Wilson's article is calculated to do great mischief, for it may be the means of stimulating other young and over-confident practitioners to undertake operations which they are incapable of performing except in a third-rate or fourth-rate manner, thus not only jeopardizing human lives without warrant, but bringing scientific surgery into disrepute with the non-discriminating public. I am myself a country practitioner, and I know whereof I write.

In my judgment, the country doctor (or any other general practitioner), who does major surgery, except in the most extreme emergencies, deserves to have his license to practice revoked.

To me it seems the baldest nonsense to talk of the country doctor doing refraction work, for any one who has tried country practice knows that, were the doctor never so well qualified, he would lack the time, and no man can become specially skilled in a special field without devoting most, if not all, of his time to it.

W. K. McCoy.

\section{Ocular Complications of Measles-The Country Doctor.}

Kalamazoo, Michi, June 11, 1906.

To the Editor:-In Tile Jounnat, May 26, there appears an item in Therapeutics on "The Ocular Complications in Measles." While in many respects there is a great deal of good advice in the article there are one or two things which it seems to me few oculists would advise. First, I am pretty sure that no one would think of using solution of cocain when intense photophobia is present. This symptom is most usually due to erosion of the cornea, and one of the great objections to 
cocain solution is just this propensity to bring about such conditions. It is better to use 5 per cent. dionin or 0.5 per cent. solution of atropin sulphate p. r. n. Second, when intense itching of the eyelids occurs, it has not been my fortune to see any good result from the Pagenstecher ointment. I should think that better results would follow the use of phenol ointment, 10 per cent.

As to the use of the spray in general catarrhal conditions, I don't believe that one child in a hundred ill with measles will let the physician use a spray, and even if it did, if there is one thing that is decidediy passe, it is the spray. A very much readier way to wash the nares of these little patients is to use the ordinary nasal douche. It is simple, effectual and cleanly. Moreover, after using it or any other form of cleansing agent (and, by the way, a simple solution of salt and baking soda-a pinch each in the douche of warm water, is the easiest, handiest and best in my judgment), the child shouid not be permitted violently to blow the nose, for fear of carrying these secretions up the Eustachian tubes.

While I am correcting what seems to me to be an error, permit me to correct another error which appeared in THE Jourval, May 19, in a very excellent article on "The Country Doctor." There was much to commend in this article, and no one can have a higher respect for the capabilities of the country doctor than I, nor do I forget for one moment that Fiphraim McDowell and Marion Sims were country doctors. The point which seems self-evident to me is the error in fancying that the specialist exists simply to impress his wonderful prowess on the non-specialist, or that the work specialists do is so unimportant that any country doctor can correct errors of refraction as well as the trained oculist. I have my doubts about this, that he can do as well and better than the average spectacle dealer (who, by the way, is not an optician even) goes without saying, but if the arerage physician with no preparation, or with a six-weeks course, can do as well as the thoroughly prepared oculists, than the ranks of the American ophthalmologic societies must be made up of some very poor timber. As a matter of fact, there is hardly a problem in medicine which calls for a more accurate and painstaking piece of work than the correction of refraction. That the doctor-country or city-should be able to tell whether or not an error of refraction exists is most necessary. I would go fur. ther and say that it is most desirable that he should be able properly to use the ophthalmoscope in his daily work. It will be of inestimable value to him. Among other things he should be able to recognize adenoids and, if need be, to operate for their removal. He can do that infinitely better and to more advantage to his patients than to correct refraction. It is remarkable how much shockingly bad work is foisted on a poor, leluded public by men with a smattering of ophthaImic knowledge.

ED. J. Bernstein.

\section{Dr. MacCormack in Lincoln County, Kentucky.}

STANFORd, KY., June 1, 1906.

To the Editor:-In the language of the "sport," Dr. J. N. MacCormack, of Bowling Green, the representative of the American Medical Association, has been "going some" during the month of May. Except it be one in the flush of full health, as is usual with Dr. MacCormack, he could ill withstand the mental and physical strain through which he has recently gone. Meeting with recognition and encouragement everywhere enables him to keep young. His itinerary, arranged for him by the council of the Kentucky State Medical Association, began on May 1 and ended on the evening of May 26. He delivered in the 26 days (Sundays excepted), 38 addresses, which, like the stories of the sea god's daughters, are neither the same, nor yet different, but as sisters should be.

I would not presume to speak for other sections, but am able to compute for the profession of Lincoln County the gain which has accrued from his recent visit to Stanford, May 16. He was announced to speak at 10 a. m., not a convenient hour, being rather early for business people to "drop everything," even to hear a political harangue, of which Kentuckians, generally, are so fond; but the large, old-fashioned court-house, one of the most ancient in the commonwealth, was filled to overflowing with gentle folk, old and voung, big and little, all anxious to listen to a new rendering of "The Relations of the Medical Profession to the Public," by a gentleman whom they had not seen, but of whom they had heard much. Suffice it that all were highly pleased as well as edified.

With the exception of three or four, who were unavoidably detained, every doctor in the county graced the occasion with his presence, and Casey, an adjoining county, sent a coterie of representative physicians.

Dr. MacCormack is so modern, so well equipped, his qualifications are so numerous, his manner and methods so fetching that to hear him before an audience is the rarest of treats. He does not indulge in polemics; his sentences mean something, he puts wit into them, emotion and satire, and when necessary, metaphorically speaking, "spanks" both the layman and the doctor-just for their own good. He is earnest, alert, openeyed, and his eagerness is so patent that every one observes his desire to do good for the great common people by his sensible, practical remarks; and the members of the profession-the boys in the trenches-feel, too, the higher and more ennolling life he pictures to them.

He wants the doctor not to neglect to-day, but to make the most of every passing hour, to fulfill his own hopes or the hopes of his friends, to be accomplished in his art, and above all, to observe the sweet amenities of life toward his fellowpractitioners.

Now, that the itinerary of Dr. MacCormack is over and gone, the aftermath is bound to be fine. We, in Lincoln, can bear flattering testimony to the efficiency of the good work done here. May harmony and peace, like a flowing river, crer be with us, as it is to-day.

Dr. MacCormack touched on a wide range of topies, but one in particular, "the mustard in the salad dressing," was that of fees for the examination of subjects for life insurance. He enumerated the $\$ 5$ and the $\$ 3$ companies. This matter is now interesting the whole profession. I may emphasize the fact that the Lincoln County Medical Society recently legislated on this question with unanimity, resolving that no member shall in the future, make an examination for an old-line company without charging and receiving therefor the fee of $\$ 5$. Verily justice should be meted out to the doctors as is done to othersthey deserve it. The recently promulgated plan of our metropolitan life companies compelling the physician, the man of standing and ability, to examine an applicant, then pass judgment on a risk of $\$ 1,000$ and paying him only $\$ 3$ for his service is an outrageous travesty on equity and justice, driving him, as it were, like sheep to the shambles; but still there are some, like Barkis, who are "willin'."

This should not prevail! Only organized effort will bring the companies "to taw" and cause them to pay a decent fee. But should they hang fire, not willing to accede to the demands of the profession, attempt the expedient, which is threatened, of doing without the doctor in $\$ 1,000$ policies, or employ (and they may find them) cut-rate examiners for this work, discomfiture may and doubtless will overtake them within a few years.

In this tour the national organizer is dealing with this aub ject in an emphatic way, and his advice will overcome the obstacles now confronting us, or at least, so alleviate them as to make them tolerable. $\mathrm{He}$ is for the doctor in and out of season. It remains with him, then, to stand stanch and true like a pig's foot. If he shies at the fear of losing a jol, he should have pasted in his chapeaux this sentiment:

"Our doubts are traitors

And make us lose the good we oft might win By fearing to attempt."

Steele Bailey, M.D.

\section{Presentation of Papers-A Just Criticism.}

Cincago, June 16, 1906

To the Lditor:-While we are still enthusiastic over the wonderful success of the Boston session and thoroughly im. pressed with the dignity and great efficiency of the machinery of the American Medical Association, would it not be well to consider some of the factors which have operated to qualify the complete satisfactoriness in some directions? 